\title{
Effect of Annealing Process on the Microstructures and Mechanical Properties of AZ31B/A356 Composite Plate Fabricated by Cast Rolling
}

\author{
Shi-jie Yang ${ }^{a} \oplus$, Yuan-dong $\mathrm{Li}^{a, b *}$, Peng-yuan Donga, Jia-ming $\mathrm{Li}^{a}$, Chi Cao ${ }^{a, b}$, Ying Ma ${ }^{a, b}$ \\ ${ }^{a}$ State Key Laboratory of Advanced Processing and Recycling of Non-ferrous Metals, Lanzhou \\ University of Technology, Lanzhou 730050, China \\ ${ }^{b}$ Key Laboratory of Non-ferrous Metal Alloys and Processing, Ministry of Education of the People's \\ Republic of China, Lanzhou University of Technology, Lanzhou 730050, China
}

Received: January 01, 2019; Revised: April 10, 2019; Accepted: May 19, 2019

\begin{abstract}
The effect of annealing process on the microstructures and mechanical properties of $\mathrm{Mg} / \mathrm{Al}$ composite plates fabricated by cast-rolling was investigated in this study. The results show that the interfacial transition zone can be divided into three regions: a $\mathrm{Mg}$ transition region, an $\mathrm{Al}$ transition region, and an intermediate region, respectively. The microhardness of the interfacial transition zone is higher than that of $\mathrm{AZ3} 1 \mathrm{~B}$ and $\mathrm{A} 356$. When the annealing temperature is $250^{\circ} \mathrm{C}$, the thermodynamic and kinetic conditions required for the formation of new intermetallic compounds have been met. While, for an annealing temperature at, or above, $300^{\circ} \mathrm{C}$, the width of the interfacial transition zone, annealing temperature, and time follow model: $(\Delta X)^{2}=2.07 \times 10^{4} \exp \left(-\frac{60407}{R T}\right)\left(t-11.54 \exp \frac{21211}{R T}\right)$. The shear strength reaches a maximum value of $116 \mathrm{MPa}$ when the annealing temperature is $200^{\circ} \mathrm{C}$. Cleavage fracture occurs at the side of the AZ31B alloy and quasi-cleavage fracture at the side of the A356 alloy.
\end{abstract}

Keywords: $\mathrm{Mg} / \mathrm{Al}$ composite plates, annealing process, interfacial transition zone, intermetallic compounds.

\section{Introduction}

Bimetallic composite plates have received considerable attention from the automobile, aerospace, and defence industries because of their improved material properties compared to those of single-layer sheet metals and alloys, especially magnesium alloy and aluminium alloy combined to form composite plate. Magnesium alloy is the lightest metal structural material, with many advantages such as high specific strength, high specific elastic, excellent damping performance, good dimensional stability, strong electromagnetic shielding capacity, abundant resources and recyclable reuse. However, its poor corrosion resistance and room temperature ductility greatly limits its widespread application ${ }^{1-5}$. By comparison, as is well-known that aluminum alloys have some advantages such as high specific strength, good plastic and strong corrosion resistance. Therefore, it is necessary to fabricate the $\mathrm{Mg} / \mathrm{Al}$ bimetallic composite plates for combining the advantages of the two alloys. On the one hand, the weight of aluminium alloy in the same volume can be reduced, andonthe other hand, the poor corrosion resistance of magnesium alloy will be overcome. The two materials benefit from each other in terms of performance and produce a synergistic effect, which makes the composite plate better than the original material, thus rendering it more able to meet various demands imposed by use in most applications ${ }^{6-11}$.

Nowadays, there are many types of processes available with which to fabricate $\mathrm{Mg} / \mathrm{Al}$ composite plates, including: diffusion bonding ${ }^{12,13}$, explosive welding ${ }^{14-16}$, insert moulding ${ }^{17}$, compound casting ${ }^{18,19}$, hot-rolling ${ }^{7,20,21}$, and so on. Macwan et al. ${ }^{5}$ have investigated both hot and cold-rolling to fabricate $\mathrm{Al} / \mathrm{Mg} / \mathrm{Al}$ three-layer composite plate, and the subsequent annealing was implemented at temperatures of $200{ }^{\circ} \mathrm{C}, 250{ }^{\circ} \mathrm{C}, 300{ }^{\circ} \mathrm{C}, 350^{\circ} \mathrm{C}$ and $400^{\circ} \mathrm{C}$ for $0.5 \mathrm{~h}, 1 \mathrm{~h}, 2 \mathrm{~h}, 4 \mathrm{~h}$, which verifies the effects on the relationship between the microstructures and the mechanical properties. It was observed that intermetallic compounds begin to appear when annealing at, and above, $250^{\circ} \mathrm{C}$ : with the increase of annealing temperature, the tensile strength first increased and then decreased, the yield strength decreased linearly, and the elongation increased. Luo et al. ${ }^{22}$ used a twopass hot-rolling process to prepare $\mathrm{Al}(5052) / \mathrm{Mg}(\mathrm{AZ31}) /$ $\mathrm{Al}(5052)$ tri-layer composite plates, however, there were no new intermetallic compounds generated in the interface of $\mathrm{Al}(5052) / \mathrm{Mg}(\mathrm{AZ31}) / \mathrm{Al}(5052)$ composite plates after the first hot-rolling pass. High-temperature annealing was carried out after the first hot-rolling pass with the purpose of understanding the effect of annealing on the evolution of interface microstructure. According to the kinetic model: $\mathrm{y}^{2}=1.98 \times 10^{6} \exp \left(-\frac{83418}{R T}\right)\left(t-0.78 \exp \frac{29770}{R T}\right)$ stablished to illustrate the growth of the intermetallic compound layers for an annealing temperature at, or above, $300{ }^{\circ} \mathrm{C}$, it was easy to see that the growth rate of the intermetallic layers increased with increasing annealing temperature, meanwhile, the incubation time decreased exponentially. 
To justify the effect of multi-pass rolling and subsequent annealing on the interface microstructure and mechanical properties, Chen et al. ${ }^{6}$ employed five-pass hot-rolling $\left(30 \%\right.$ reduction, $400{ }^{\circ} \mathrm{C}$ ) and annealed the specimens at 200 ${ }^{\circ} \mathrm{C}, 300{ }^{\circ} \mathrm{C}$, and $400{ }^{\circ} \mathrm{C}$ for $1 \mathrm{~h}$ and $2 \mathrm{~h}$ after hot-rolling. The experimental results demonstrated that the width of bond interface layer increased with increasing annealing temperature and holding time. With the increase of annealing temperature and holding time, the mechanical properties first increased, then decreased. The mechanical properties achieved their maximum values after annealing at $200{ }^{\circ} \mathrm{C}$ for $2 \mathrm{~h}$.

At time of writing, few studies have been reported on the solid-liquid composite method to fabricate the $\mathrm{Mg} / \mathrm{Al}$ composite plates. $\mathrm{Mg} / \mathrm{Al}$ composite plates were prepared by solid-liquid cast-rolling in this paper; because of the work hardening of $\mathrm{Mg} / \mathrm{Al}$ composite plates after cast-rolling, the effect of the annealing process on the evolution of microstructure and the mechanical properties was deemed worthy of investigation. The purpose of this is to obtain $\mathrm{Mg} / \mathrm{Al}$ composite plates of sound appearance and excellent performance. Not only can this work open up new avenues for the fabrication and optimisation of $\mathrm{Mg} / \mathrm{Al}$ composite plates, it also provides guidance for practical production and application of $\mathrm{Mg} / \mathrm{Al}$ composite plates. The present work aims to analyse the effects of annealing process on the relationship between microstructure formation mechanism and mechanical properties of $\mathrm{Mg} / \mathrm{Al}$ composite plates.

\section{Experimental Procedure}

\subsection{Materials}

The chemical compositions of experimental materials for cast-rolling AZ31B magnesium alloy and A356 aluminium alloy are shown in Table 1. Cast aluminium alloy A356 has good liquid forming ability and wrought magnesium alloy AZ31B has good plastic forming ability at high temperature.

\subsection{Cast Rolling Process}

The dimensions of base sheets which were cut from AZ31B magnesium alloy plates are $100 \mathrm{~mm} \times 100 \mathrm{~mm} \times 2$ $\mathrm{mm}$, and A356 aluminium alloy ingots were melted to form the covering metal. Before cast-rolling, it was necessary to polish the surfaces of AZ31B sheets, to reduce the thickness of oxide films and the surface roughness, by sandpaper or wire brushing. Then the AZ31B sheets were soaked in an ultrasonic cleaner containing acetone for $10 \mathrm{~min}$ to remove oil stains: specimens were then dried in cold air. The base sheets of AZ31B alloy were kept in SX2-4-10 box-type resistance furnace
(Shanghai Zhongyi electric furnace co., LTD, China) at $150^{\circ} \mathrm{C}$ for $30 \mathrm{~min}$ after surface treatment. Meanwhile, the A356 aluminium alloy ingots were melted in a $7.5 \mathrm{~kW}$ well-type resistance furnace (Shanghai Shiyan electric furnace co., LTD, China), and then refined by utilising $1 \% \mathrm{wt} . \% \mathrm{C}_{2} \mathrm{Cl}_{6}$ at $740{ }^{\circ} \mathrm{C}$. The melt was held in air and was continuously and evenly cast on an $\mathrm{AZ} 31 \mathrm{~B}$ sheet previously insulated to $150^{\circ} \mathrm{C}$ when the melt temperature decreased to $640{ }^{\circ} \mathrm{C}$. At the same time, the rolling machine was started, and the two as-obtained types of alloys with an upper liquid phase and lower solid phase were fed into the gap between the rollers. The chosen rolling speed was $6 \mathrm{rpm}$, the gap between the twin rollers was set to $3 \mathrm{~mm}$, the diameter of each roller was $180 \mathrm{~mm}$, and the maximum rolling force was $420 \mathrm{kN}$ (Figure 1). When the two types of alloys were firmly combined, the rolled composite plate was finally synthesised and then air-cooled to room temperature.

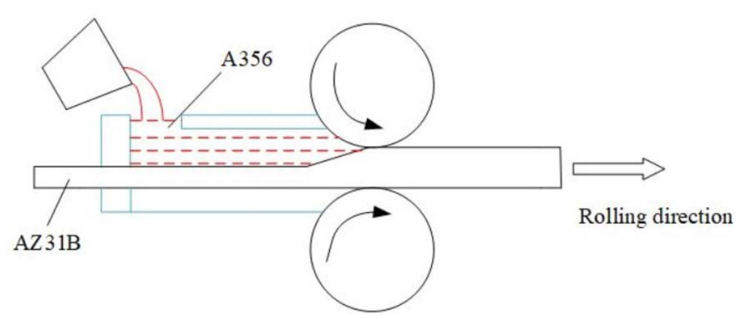

Figure 1. Schematic diagram of the rolling process.

\subsection{Subsequent Annealing Treatments}

The annealing temperatures and times were set tot 150 ${ }^{\circ} \mathrm{C}, 200{ }^{\circ} \mathrm{C}, 250{ }^{\circ} \mathrm{C}, 300{ }^{\circ} \mathrm{C}, 350{ }^{\circ} \mathrm{C}$, and $400{ }^{\circ} \mathrm{C}$ for $30 \mathrm{~min}$, $60 \mathrm{~min}, 90 \mathrm{~min}, 120 \mathrm{~min}$, and $180 \mathrm{~min}$ on the as-fabricated $\mathrm{Mg} / \mathrm{Al}$ composite plates.

\subsection{Microstructure Characterization}

The metallographic samples were cut from the composite plates under different annealing parameters for grinding and polishing. The polishing liquid was an $\mathrm{Al}_{2} \mathrm{O}_{3}$ solution. Subsequently, a $4 \%$ nitric acid solution was used to etch the AZ31B side near the interface, and the A356 side near the interface was etched in a saturated sodium hydroxide solution ( $100 \mathrm{~g}$ of sodium hydroxide dissolved in $100 \mathrm{ml}$ of water, stirred quickly until the solution was free of sodium hydroxide particles). The microstructure morphology of the etched metallographic samples were observed by QUANTA FEG-450 thermal field emission scanning electron microscope (SEM) with energy disperse spectroscopy (EDS) and electron backscatter diffraction (EBSD; Oxford instruments) equipped with HKL Channel 5 which was also used to observe and analyse the samples on both sides that had undergone polish ingin ion milling.

Table 1. Chemical compositions of AZ31B magnesium alloy and A356 aluminum alloy (mass fraction/\%).

\begin{tabular}{ccccccccc}
\hline Alloy & $\mathrm{Al}$ & $\mathrm{Si}$ & $\mathrm{Mg}$ & $\mathrm{Fe}$ & $\mathrm{Mn}$ & $\mathrm{Zn}$ & $\mathrm{Cu}$ & $\mathrm{Ti}$ \\
\hline AZ31B & 3.17 & 0.25 & Bal. & - & 0.2 & 1.1 & 0.08 & - \\
A356 & Bal. & 7.5 & 0.45 & 0.2 & 0.1 & 0.2 & 0.2 & 0.2 \\
\hline
\end{tabular}


Their working voltage were $15 \mathrm{kV}$. The microstructure of the AZ31B sides was observed by Axio Scope A1 optical microscope (OM). The type and content of phase on fracture of shear samples were detected by means of D/max-2400 X ray diffractometer $(\mathrm{XRD})$ with $\mathrm{Cu} \mathrm{K} \alpha$ radiation.

\subsection{Mechanical Properties}

An HV-100 Vickers microhardness tester (Shanghai Shendao technology and trade co., LTD, China) with an applied load of $100 \mathrm{~g}(0.98 \mathrm{~N})$ and a dwell time of $15 \mathrm{~s}$ was used to measure the hardness of the interfacial transition zone of the $\mathrm{Mg} / \mathrm{Al}$ composite plates. The shear strength of the composite plates was measured in a WDW-100D electronic universal material testing machine (Jinan Zhongnuo instrument co. LTD, China) with a cross-head speed of $1 \mathrm{~mm} /$ min, the method for determining the shear strength in this paper was the pull-shearing method. The shear strength, $\tau$, was expressed by the shear stress per unit area. The formula was as follows:

$$
\tau=\frac{F}{b \times l}
$$

where $b$ and $l$ were the length and width of shear interface, respectively. In this paper, $b=4 \mathrm{~mm}, 1=4 \mathrm{~mm}$.

\section{Results and Discussion}

\subsection{Evolution of Microstructure near the Interfacial Transition Zone}

The inverse pole figure (IPF) maps and phase maps of the composite plates are shown in Figure 2, which shows the as-rolled specimen after being annealed at $250{ }^{\circ} \mathrm{C}$ for $180 \mathrm{~min}$. That the microstructure of the grains after annealing differs from that of the as-rolled specimen can be seen from Figure 2. The grains in the as-rolled state have a preferred orientation, while the grains after annealing are distributed uniformly, especially on the side of the AZ31B alloy. The A356 alloy, applied at $640{ }^{\circ} \mathrm{C}$, covered the AZ31B sheets which were maintained 150 ${ }^{\circ} \mathrm{C}$, so, because the temperature was so high, dynamic recovery and recrystallization occurred on these bilateral alloy specimens during rolling. Meanwhile, areal distortion was caused by grain deformation, where new fine, equiaxial, grains formed; however, the degrees of dynamic recovery and recrystallization was low due to the short rolling process. Figure 3 is provided to compare the recrystallization under as-rolled and as-annealed conditions.
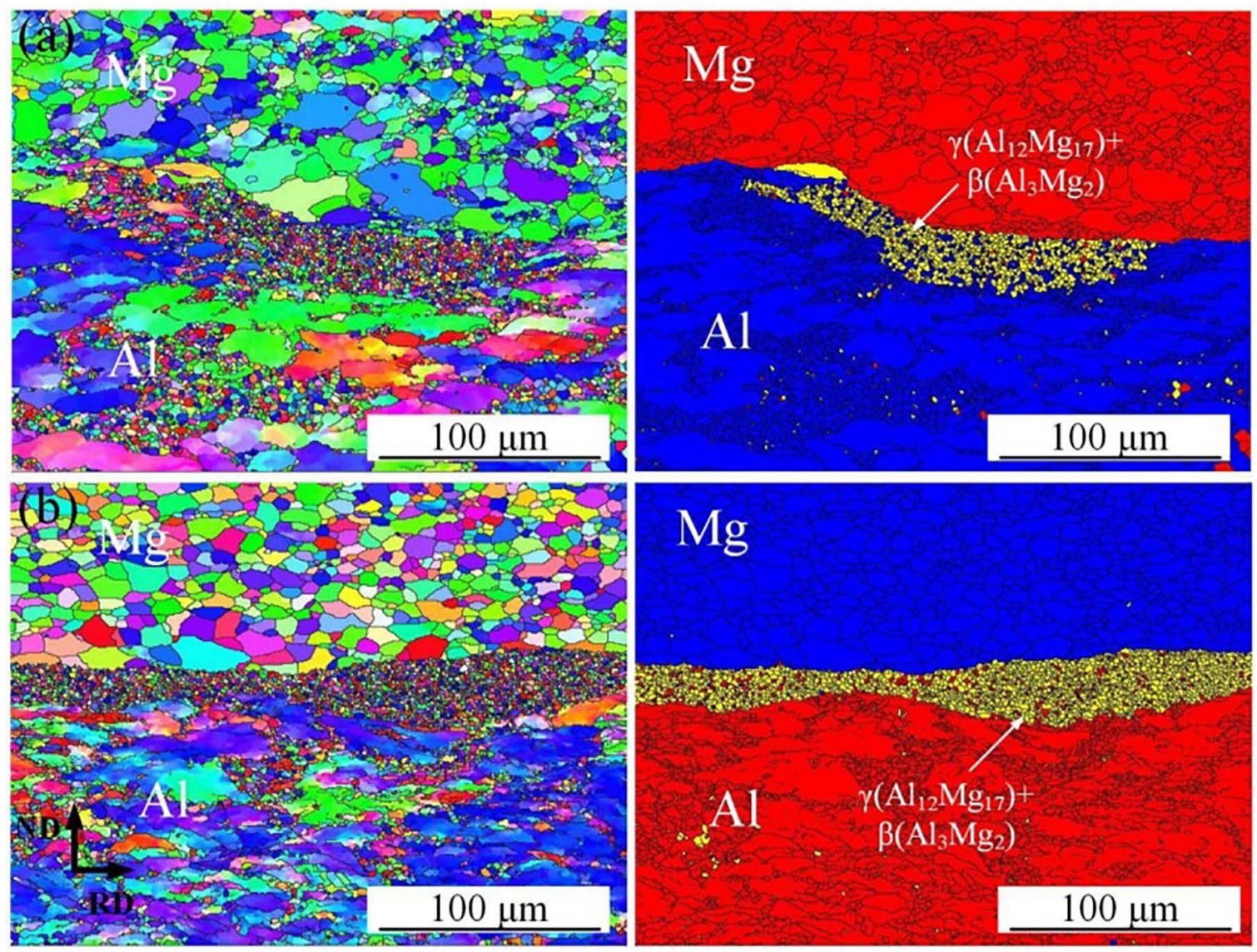

Figure 2. Inverse pole figure (IPF) maps and phase maps of SEM/EBSD images obtained from $\mathrm{Mg} / \mathrm{Al}$ composite plates (a) as-rolled, (b) annealed at $250^{\circ} \mathrm{C}$ for $180 \mathrm{~min}$. 

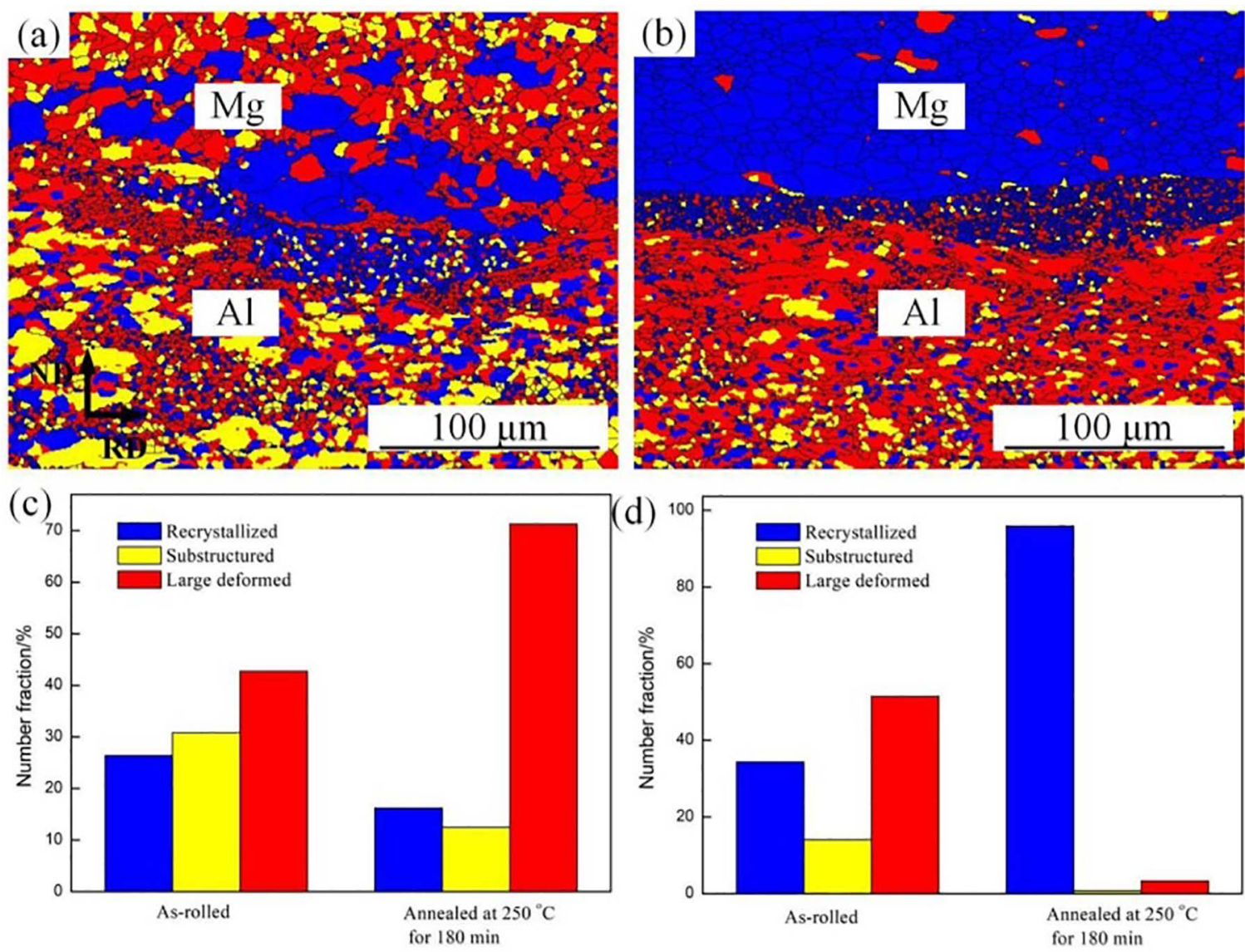

Figure 3. IPF of AZ31B/A356 composite plates (blue-recrystallized; yellow-substructured; red-large deformed): (a) as-rolled; (b) annealed at $250{ }^{\circ} \mathrm{C}$ for $180 \mathrm{~min}$; and the number fractions of recrystallized, substructured and large deformed grains in AZ31B/A356 composite plates: (c) A356 side; (d) AZ31B side.

The recrystallization volume fractions of magnesium and aluminium alloys of the as-rolled specimens were $34 \%$ and $26 \%$, respectively: corresponding to this, the proportion of low-angle grain boundaries (LAGB) were $35.3 \%$ and $32.2 \%$, respectively. After annealing at $250{ }^{\circ} \mathrm{C}$ for 180 min, sub-crystalline migration nucleation had begun in the distorted areas on the AZ31B side (i.e., static recrystallization during annealing). The grains of the as-rolled specimens have a preferred orientation and are replaced by small isotropic grains after annealing. Compared with the asrolled sample, the degree of preferred orientation is reduced with the appearance of a large number of equiaxial grains. Simultaneously, the recrystallization volume fraction of the AZ31B side reached $96 \%$. As a result, a state of nearcomplete recrystallization is thus achieved. The volume fraction of LAGB decreases significantly. On the contrary, the volume fraction of high-angle grain boundaries (HAGB) increases, which also indicates that the dislocation density decreases. The recrystallization volume fraction on the A356 side is $16 \%$, which is lower than that of the as-rolled specimens. This is mainly attributed to the sub-crystalline merging nucleation mechanism of aluminium grains.
The dynamic recrystallization causes grains to merge and grow after annealing. Moreover, the degree of recrystallization on the side of the A356 alloy is low. Nie et al. ${ }^{23}$ reported similar research results in which the number of recrystallized $\mathrm{Al}$ grains shows little difference at low annealing temperatures. After annealing, the proportion of LAGB at the AZ31B side decreases to $4.3 \%$, which is significantly lower than the $29.8 \%$ measured on the A356 side. These indicate that the recrystallization on the magnesium side is more complete than that on the aluminium side, which also confirms that the recrystallization temperature of aluminium is higher than that of magnesium. Fronczek et al. ${ }^{24}$ reported a similar effect whereby a fine microstructure is typical for $\mathrm{Mg}$, while some Al grains retained a preferred orientation. In the meantime, it can be observed from Figure 2 that the interface microstructure of the sample differs from that of the bilateral alloys, so to distinguish them expediently, the interface is called the interfacial transition zone. According to Figure 2, the interfacial transition zone mainly consists of yellow which represents the $\mathrm{Mg}_{17} \mathrm{Al}_{12}$, with another colour mixed in simultaneously (perhaps $\mathrm{Al}_{3} \mathrm{Mg}_{2}$ ). A similar investigation was reported by Kim et al. ${ }^{25}$. 
Therefore, it is believed that the interfacial transition zone may generate intermetallic compounds $\mathrm{Mg}_{17} \mathrm{Al}_{12}$ and $\mathrm{Al}_{3} \mathrm{Mg}_{2}$, and the volume fraction of $\mathrm{Mg}_{17} \mathrm{Al}_{12}$ is much higher than that of $\mathrm{Al}_{3} \mathrm{Mg}_{2}$. It can be also seen that the intermetallic compounds, and width of the interfacial transition zone of $26 \mu \mathrm{m}$, do not change after annealing: however, the intermetallic compounds in the interfacial transition zone show continuity of state compared with the as-rolled specimens, which shows that an annealing temperature of $250^{\circ} \mathrm{C}$ satisfies the thermodynamic and kinetic conditions for forming $\mathrm{Mg}-\mathrm{Al}$ intermetallic compounds, thus a small number of intermetallic compounds have begun to form in the interfacial transition zone.

\subsection{Microstructure of the Magnesium Alloy Side}

The OM photographs of the AZ31B magnesium alloy at one side of this $\mathrm{Mg} / \mathrm{Al}$ composite plate, under different conditions are shown Figure 4: annealing temperature exerts a significant influence on the size and orientation of grains. The majority of the grains of the as-rolled specimens have a preferred orientation (Figure 4a). It is also observed that the diameter of the largest grain is greater than $30 \mu \mathrm{m}$ and there are some tiny grains around the coarse grains, resulting in the formation of a typical strip-like structure, which arises mainly because of the chilling effect of the rollers and the process of hot-rolling being so short that the degree of dynamic recrystallization on the magnesium alloy side is low. Lee et al. ${ }^{20}$ and Chen et al. ${ }^{6}$ also observed a similar phenomenon when investigating the effect of annealing processes on the microstructure of AZ31B. When the annealing temperature is $150{ }^{\circ} \mathrm{C}$ or $200{ }^{\circ} \mathrm{C}$, compared with the as-rolled specimens, the tiny grains start growing, but grain orientations have not changed significantly. When the annealing temperature reaches $250{ }^{\circ} \mathrm{C}$, as shown in Figure $4 d$, the magnesium alloy side generally achieves a state of complete recrystallization and the preferred orientation disappears. In the areas of serious distortion, where many new crystal nuclei are generated, the grains with a deformed texture tend to form fine, isotropic, equiaxial grains. Part of the driving force required is provided by the annealing process and the remainder comes from the strain energy stored in the surrounding deformed grains during recrystallization. When the annealing temperature was at, or above, $300^{\circ} \mathrm{C}$, as can be seen from Figures $4 \mathrm{e}$ and $\mathrm{f}$, the grains on the magnesium alloy side continue to grow after complete recrystallization, the driving force behind this grain growth being supplied by a reduction in total grain boundary energy ${ }^{26}$, such that the grain boundaries move towards the centre of curvature to render themselves flat. Eventually the grain boundaries migrate, overlap, and coalesce. Furthermore, the rate of migration of the grain boundaries increased with the increase of annealing temperature, which leads to the rapid increase in grain size.

\subsection{Thermodynamics and Diffusion Kinetics}

Due to low annealing temperatures having limited effects on the formation of intermetallic compounds in the interfacial transition zone, it is necessary to investigate the effects of high annealing temperatures on the interfacial transition zone. SEM images and the width values of the interfacial transition zone at $300{ }^{\circ} \mathrm{C}, 350{ }^{\circ} \mathrm{C}$, and $400{ }^{\circ} \mathrm{C}$ annealed for $30 \mathrm{~min}, 60 \mathrm{~min}, 90 \mathrm{~min}, 120 \mathrm{~min}$, and 180 min are shown in Figure 5 and Table 2, respectively: it can be seen that the width of the interfacial transition zone increases with the increase of annealing temperature and time (In Table 2, $26 \mu \mathrm{m}$ is the average width of the interfacial transition zone in the as-rolled state, $\Delta X$ is the increment of the width of interfacial transition zone under different annealing conditions). Since the earliest intermetallic compounds need a certain transition time in which to nucleate, this time is referred to as the incubation period $^{22}$. Therefore, the kinetic model linking the interfacial transition zone width, annealing temperature, and time is as follows ${ }^{12,27}$ :

$$
(\Delta X)^{2}=D\left(t-t_{0}\right)
$$

where $\Delta X$ is the increment of the width of the interface transition zone $(\mu \mathrm{m}), D$ is the diffusion coefficient of elements and intermetallic compounds $\left(\mu \mathrm{m}^{2} / \mathrm{s}\right), t$ is the annealing time (s), and $t_{0}$ is the incubation period (s) (Table 2 and Figure 6). The diffusion coefficient $D$ and incubation period $t_{0}$ of intermetallic compounds at each annealing temperature can be obtained from the slope and intercept of the best-fit line (Table 3).The incubation period is given by:

$$
t_{0}=k \exp \frac{E}{R T}
$$

Where $k$ is the precipitation constant of reaction phase, $E$ is the activation energy $(\mathrm{J} / \mathrm{mol})$ of the precipitation component ( $\mathrm{J} / \mathrm{mol}), R$ is the Boltzmann constant, $8.314 \mathrm{~J} /(\mathrm{mol} \bullet \mathrm{K})$, and $T$ is the thermodynamic temperature $(\mathrm{K})$. Taking the logarithm of both sides of Eq. (2) gives:

$$
\ln t_{0}=\ln k+\frac{E}{R T}
$$

Substituting the values of $t_{0}$ at different temperatures into Eq. (3), the $\ln t_{0}-1 / T$ plot is found by linear fitting to the data. The slope and the intercept of the line are $E / R$ and $\ln k$, respectively. After calculation, $E$ is found to be $21,211 \mathrm{~J} / \mathrm{mol}$, and $k$ is 11.54 : based on the data in Table 3, the incubation period decreases exponentially with increased annealing temperature. 

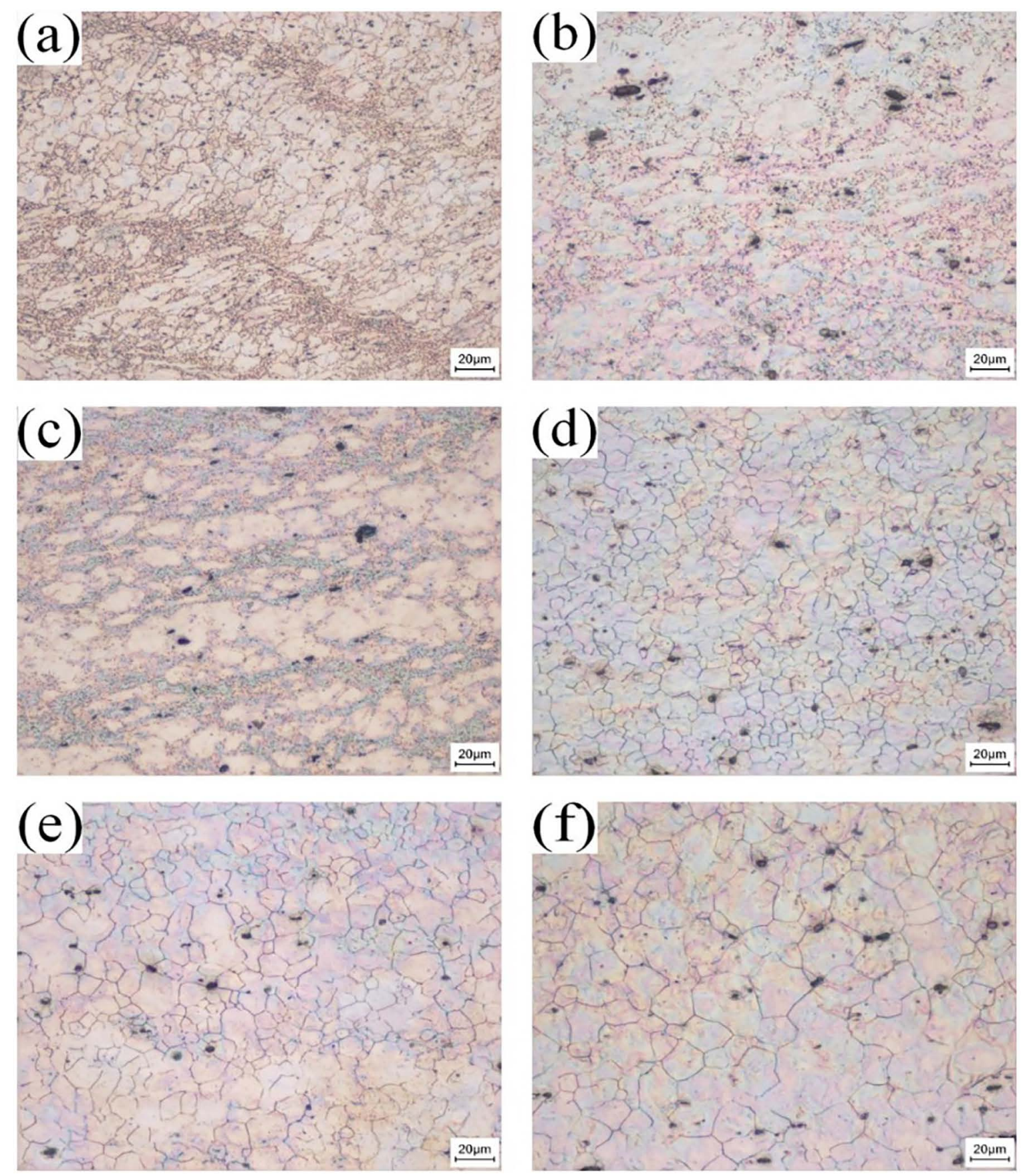

Figure 4. OM photographs of AZ31B magnesium alloy side (a) as-rolled, annealed for $180 \mathrm{~min}$ (b) $150{ }^{\circ} \mathrm{C}$, (c) $200{ }^{\circ} \mathrm{C}$, (d) $250{ }^{\circ} \mathrm{C}$, (e) $300{ }^{\circ} \mathrm{C}$, (f) $400{ }^{\circ} \mathrm{C}$.

Table 2. Widths of the interfacial transition zone under different annealing conditions.

\begin{tabular}{cccc}
\hline \multirow{2}{*}{ Annealing time/min } & \multicolumn{3}{c}{ Width $(26+\Delta \mathrm{X}) / \mu \mathrm{m}$} \\
\cline { 2 - 4 } & $300^{\circ} \mathrm{C}$ & $350^{\circ} \mathrm{C}$ & $400{ }^{\circ} \mathrm{C}$ \\
\hline 30 & $26+9$ & $26+18$ & $26+28$ \\
60 & $26+13$ & $26+26$ & $26+43$ \\
90 & $26+16$ & $26+30$ & $26+53$ \\
120 & $26+20$ & $26+35$ & $26+62$ \\
180 & $26+26$ & $26+41$ & $26+69$ \\
\hline
\end{tabular}



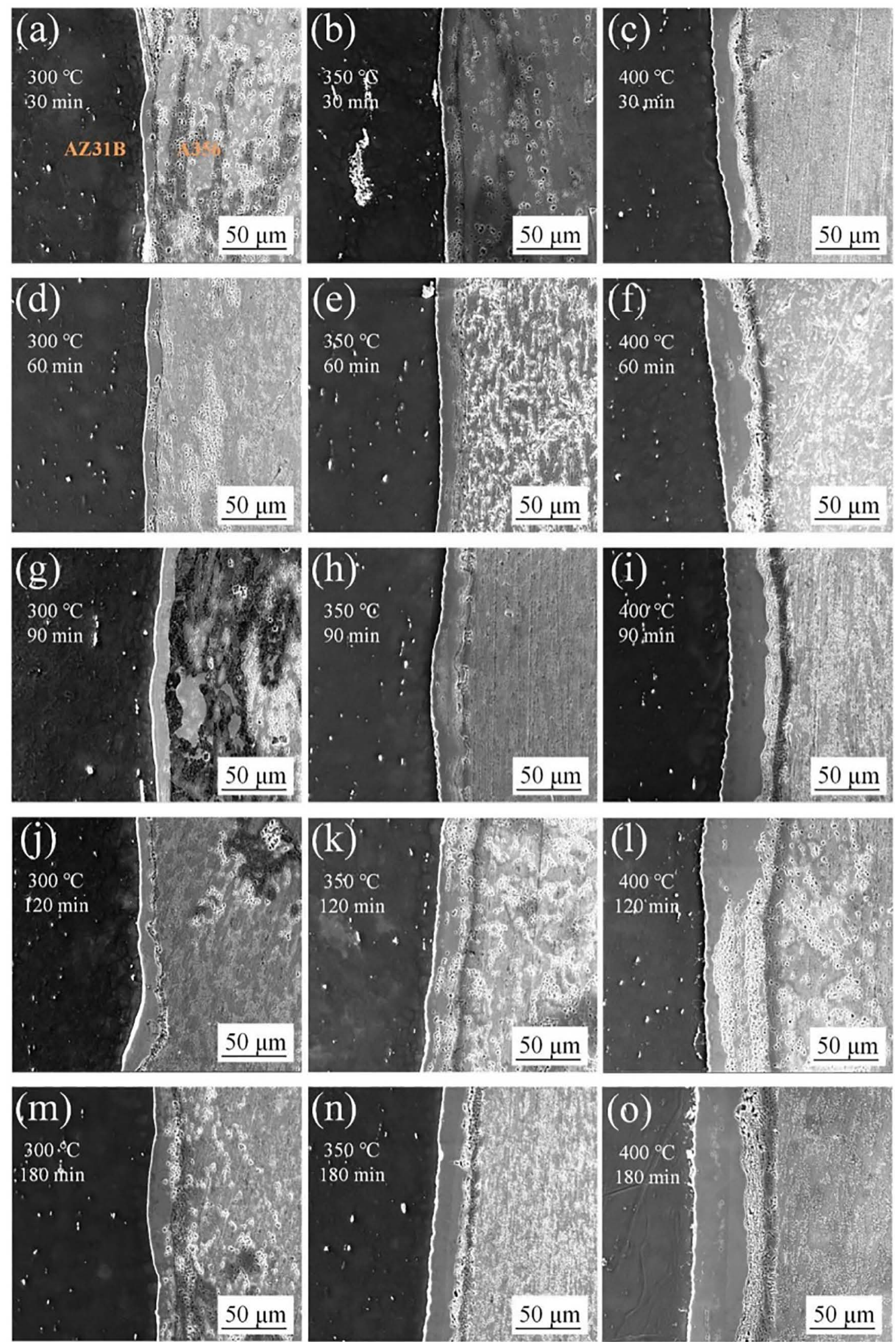

Figure 5. SEM images of the interfacial transition zone annealed at $300^{\circ} \mathrm{C}, 350^{\circ} \mathrm{C}$ and $400^{\circ} \mathrm{C}$ for $30 \mathrm{~min}, 60 \mathrm{~min}, 90 \mathrm{~min}, 120 \mathrm{~min}$ and $180 \mathrm{~min}$. 


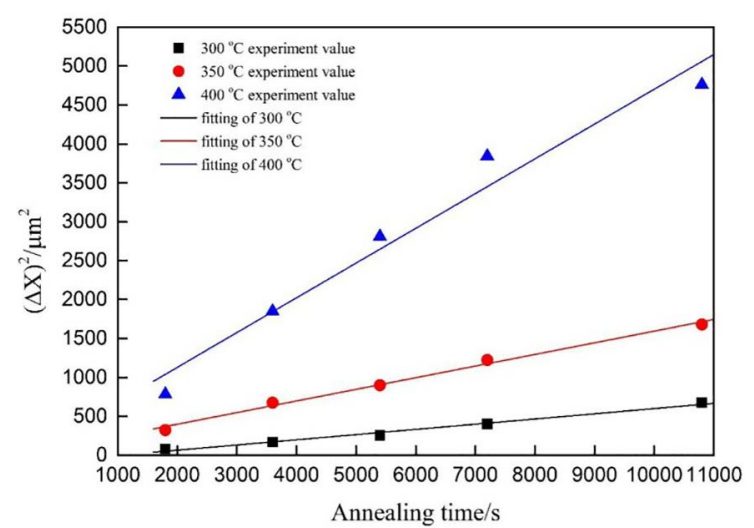

Figure 6. The increment of the width of the interfacial transition zone at different annealing temperatures for different annealing times ( $\triangle \mathrm{X}$ is the increment of the width of interfacial transition zone).

Table 3. Kinetic parameters at various annealing temperatures.

\begin{tabular}{ccc}
\hline Annealing temperature $/{ }^{\circ} \mathrm{C}$ & $\mathrm{D}\left(\mu \mathrm{m}^{2} / \mathrm{s}\right)$ & $\mathrm{t}_{0}(\mathrm{~s})$ \\
\hline 300 & 0.067 & 1026.3 \\
350 & 0.150 & 669.7 \\
400 & 0.447 & 528.9 \\
\hline
\end{tabular}

According to the atomic diffusion mechanism, the atoms deviate from their equilibrium positions to migrate by means of the diffusion activation energy. Diffusion coefficients vary with the temperature. The diffusion coefficient and annealing temperature satisfy the Arrhenius equation:

$$
D=D_{0} \exp \left(\frac{-Q}{R T}\right)
$$

Where $D$ is the diffusion coefficient of elements and intermetallic compounds $\left(\mathrm{m}^{2} / \mathrm{s}\right), D_{0}$ is self-diffusion constant $\left(\mathrm{m}^{2} / \mathrm{s}\right), Q$ is the diffusion activation energy $(\mathrm{J} / \mathrm{mol})$, and $T$ is the annealing temperature $(\mathrm{K})$. Taking the logarithm of both sides of Eq. (4) gives:

$$
\ln D=\ln D_{0}-\frac{Q}{R T}
$$

Substituting the values of D in Table 3 into Eq. (5), and the values of $Q$ and $D_{0}$ can be obtained by linear fitting, $Q=60,407$ $\mathrm{J} / \mathrm{mol}, D_{0}=2.07 \times 10^{4} \mathrm{~m}^{2} / \mathrm{s}$. Combining Eqs. (4) and (1) gives:

$$
(\Delta X)^{2}=D_{0} \exp \left(-\frac{Q}{R T}\right)\left(t-t_{0}\right)
$$

Substituting the calculated values of $Q$ and $D_{0}$ into Eq. (6), the relationship linking the increment of the width of the interfacial transition zone, annealing temperature, and time can be described by the following kinetic model:

$$
\begin{gathered}
(\Delta X)^{2}=2.07 \times 10^{4} \exp \left(-\frac{60407}{R T}\right) \\
\left(t-11.54 \exp \frac{21211}{R T}\right)
\end{gathered}
$$

Figure 7 shows comparison results that the increment of width of the interfacial transition zone in experimental and calculated conditions. As can be seen from Figure 7 , the diffusion distance of intermetallic compounds is more sensitive to annealing temperature than annealing time. Therefore, annealing temperature plays the dominant role in influencing the width of the interfacial transition zone.

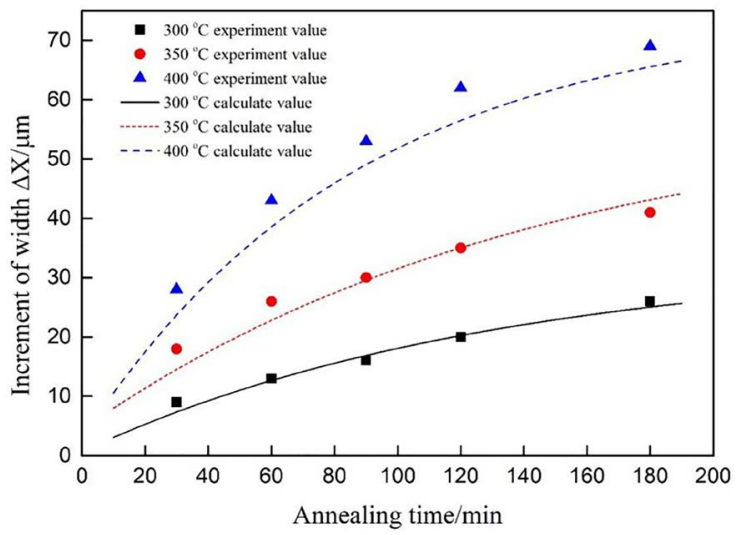

Figure 7. The comparison of width increment of the interfacial transition zone between experiment and calculation.

\subsection{Phase Composition in the Interface Transition Zone}

The microstructure of the interfacial transition zone of the composite plate is different from that of the bilateral alloys, so it is important to learn of the phase composition of the interfacial transition zone. When A356 aluminium alloy liquids (at $640{ }^{\circ} \mathrm{C}$ ) cover an AZ31B sheet which is heated to $150{ }^{\circ} \mathrm{C}$, the surface of the AZ31B sheet melts and the atoms collide with each other violently. The release of latent heat of crystallization during solidification causes the interfacial transition zone to stabilise at higher temperatures. According to the $\mathrm{Mg}-\mathrm{Al}$ and $\mathrm{Mg}$-Si binary phase diagrams ${ }^{28,29}$, when the area contains $59.8 \% \mathrm{Mg}$ (mass fraction) and $40.2 \% \mathrm{Al}$ (mass fraction) or $36.1 \%$ $\mathrm{Mg}$ (mass fraction) and $63.9 \% \mathrm{Al}$ (mass fraction), and the corresponding eutectic reaction temperature is reached, this produces the intermetallic compounds $\mathrm{Al}_{3} \mathrm{Mg}_{2}$ and $\mathrm{Mg}_{17} \mathrm{Al}_{12}:\left(438{ }^{\circ} \mathrm{C}\right) \mathrm{L} \leftrightharpoons \delta-\mathrm{Mg}+\gamma\left(\mathrm{Al}_{12} \mathrm{Mg}_{17}\right),\left(450{ }^{\circ} \mathrm{C}\right)$ $\mathrm{L} \leftrightharpoons \alpha-\mathrm{Al}+\beta\left(\mathrm{Al}_{3} \mathrm{Mg}_{2}\right)$. Where the area contains $63.2 \%$ $\mathrm{Mg}$ (mass fraction) and $36.8 \% \mathrm{Si}$ (mass fraction), this generates the intermetallic compounds $\mathrm{Mg}_{2} \mathrm{Si}:\left(637^{\circ} \mathrm{C}\right)$ $\mathrm{L} \leftrightharpoons(\mathrm{Mg})+\mathrm{Mg}_{2} \mathrm{Si}$. SEM-EDS point scanning detection and analysis were performed on the interfacial transition zone (Figure 8). The point scanning results and possible phases are listed in Table 4. So it can be concluded that three intermetallic compounds are formed in the interfacial transition zone of the as-rolled. Compared with the asrolled specimens, the as-annealed elemental $\mathrm{Mg}, \mathrm{Al}$, and Si contents all follow the same proportional relationship. 


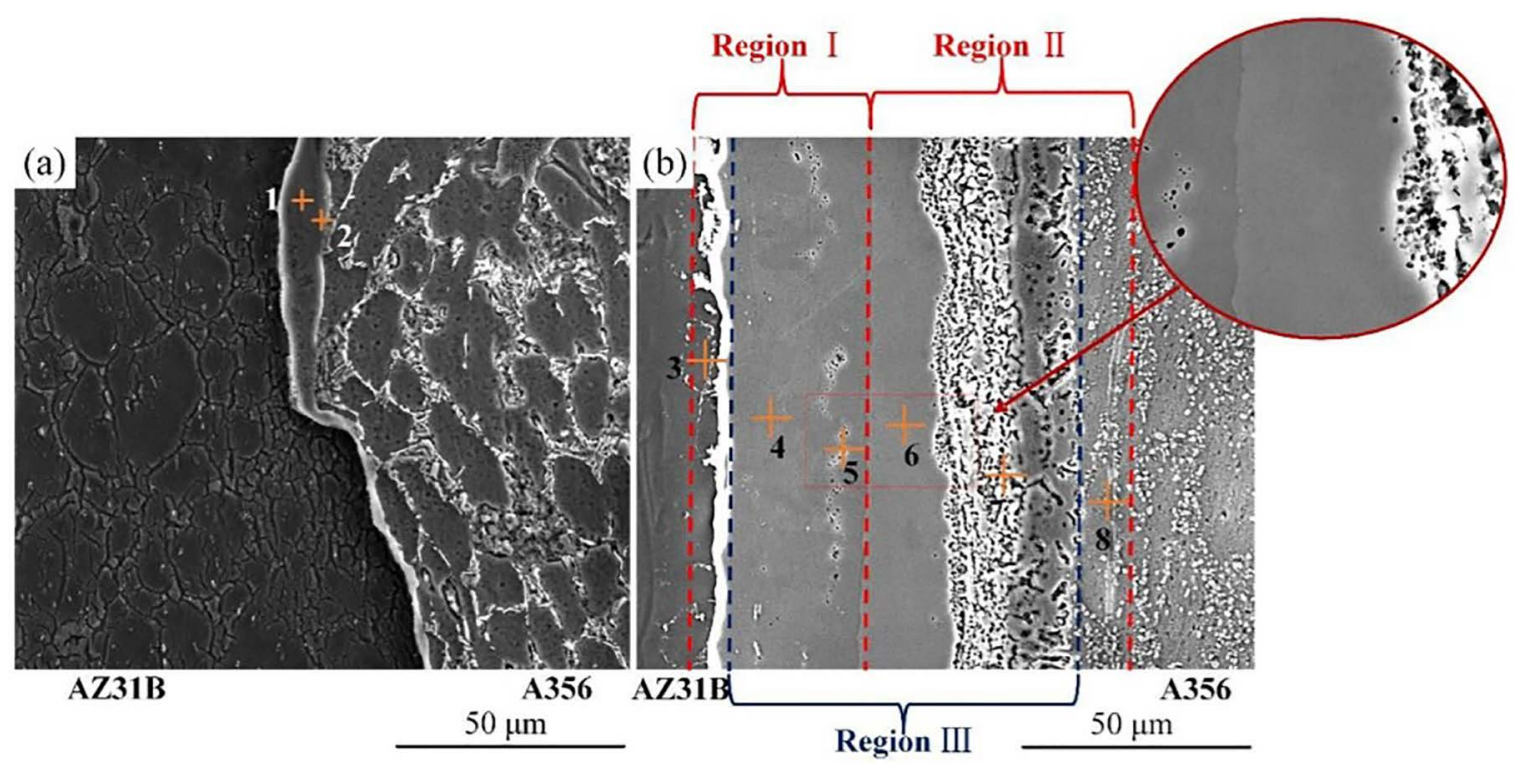

Figure 8. SEM images and EDS local point scanning composition analysis on the interfacial transition zone of $\mathrm{Mg} / \mathrm{Al}$ composite plate under different conditions: (a) as-rolled, (b) annealed at $400^{\circ} \mathrm{C}$ for $180 \mathrm{~min}$.

Table 4. Point scanning results and possible phase present in interfacial transition zone of $\mathrm{Mg} / \mathrm{Al}$ composite plate (mass fraction/\%).

\begin{tabular}{ccccc}
\hline Point & $\mathrm{Mg}$ & $\mathrm{Al}$ & $\mathrm{Si}$ & Possible phase \\
\hline 1 & 57.0 & 43.0 & 0.0 & $\gamma\left(\mathrm{Al}_{12} \mathrm{Mg}_{17}\right)$ \\
2 & 34.4 & 59.6 & 6.0 & $\beta\left(\mathrm{Al}_{3} \mathrm{Mg}_{2}\right), \mathrm{Mg}_{2} \mathrm{Si}$ \\
3 & 87.2 & 12.8 & 0.0 & $\delta-\mathrm{Mg}$ \\
4 & 58.6 & 41.4 & 0.0 & $\gamma\left(\mathrm{Al}_{12} \mathrm{Mg}_{17}\right)$ \\
5 & 56.8 & 41.7 & 1.5 & $\gamma\left(\mathrm{Al}_{12} \mathrm{Mg}_{17}\right), \mathrm{Mg}_{2} \mathrm{Si}$ \\
6 & 38.5 & 61.5 & 0.0 & $\beta\left(\mathrm{Al}_{3} \mathrm{Mg}_{2}\right)$ \\
7 & 37.7 & 59.3 & 3.0 & $\beta\left(\mathrm{Al}_{3} \mathrm{Mg}_{2}\right), \mathrm{Mg}_{2} \mathrm{Si}$ \\
8 & 13.1 & 85.7 & 1.2 & $\alpha-\mathrm{Al}$ \\
\hline
\end{tabular}

Therefore, it can be proved that there is no change in the phase type of the interfacial transition zone after annealing, yet the volume fraction of $\mathrm{Mg}-\mathrm{Al}$ intermetallic compounds increases significantly. When the annealing temperature is at, or above, $250{ }^{\circ} \mathrm{C}$, the thermodynamic and kinetic conditions for forming $\mathrm{Mg}-\mathrm{Al}$ intermetallic compounds are met: $2 \mathrm{Mg}+3 \mathrm{Al}=\mathrm{Al}_{3} \mathrm{Mg}_{2}, 17 \mathrm{Mg}+12 \mathrm{Al}=\mathrm{Al}_{12} \mathrm{Mg}_{17}{ }^{30}$, and new phases start to form and continue to diffuse toward the bilateral alloys. When the temperature is between $540{ }^{\circ} \mathrm{C}$ and $580{ }^{\circ} \mathrm{C}$, the reaction $2 \mathrm{Mg}+\mathrm{Si}=\mathrm{Mg}_{2} \mathrm{Si}$ will satisfy the thermodynamic condition ${ }^{31}$, but the annealing temperatures used in this present work do not yet provide sufficient conditions for the generation of $\mathrm{Mg}_{2} \mathrm{Si}$, so new $\mathrm{Mg}_{2} \mathrm{Si}$ will not generally be formed. Depending on the type and distribution of the phases, the interfacial transition zone of $\mathrm{Mg} / \mathrm{Al}$ composite plate can be divided into three regions ${ }^{17}$ : a $\mathrm{Mg}$ transition region (region I) consisting of $\delta$ - $\mathrm{Mg}, \mathrm{Mg}_{17} \mathrm{Al}_{12}$ and $\mathrm{Mg}_{2} \mathrm{Si}$ formed near the AZ31B side, an $\mathrm{Al}$ transition region (region II) consisting of $\alpha-\mathrm{Al}, \mathrm{Al}_{3} \mathrm{Mg}_{2}$ and $\mathrm{Mg}_{2} \mathrm{Si}$ formed near the $\mathrm{A} 356$ side, and an intermediate region (region III) is composed of $\mathrm{Mg}_{17} \mathrm{Al}_{12}, \mathrm{Mg}_{2} \mathrm{Si}$, and $\mathrm{Al}_{3} \mathrm{Mg}_{2}$, respectively. As can be seen from Figure 8 , in contrast to the results shown in Figure 2, the width of region II is significantly greater than that of region $I$. This is mainly attributed to the diffusion activation energy $Q$ of the intermetallic compound $\mathrm{Al}_{3} \mathrm{Mg}_{2}$ being less than that of $\mathrm{Mg}_{17} \mathrm{Al}_{12}{ }^{32}$. According to these discussed phenomena, the formation process of different in the interfacial transition zone can be speculated, as shown in Figure 9.

\subsection{Microhardness}

The Vickers microhardness test results, in the vertical interface direction of the $\mathrm{Mg} / \mathrm{Al}$ composite plates under different conditions, are shown in Figure 10. The samples of composite plates were loaded from their AZ31B side to their A356 side in turn on a Vickers microhardness tester. All microhardness values are expressed as the average values obtained from five repeated tests on the same sample. 

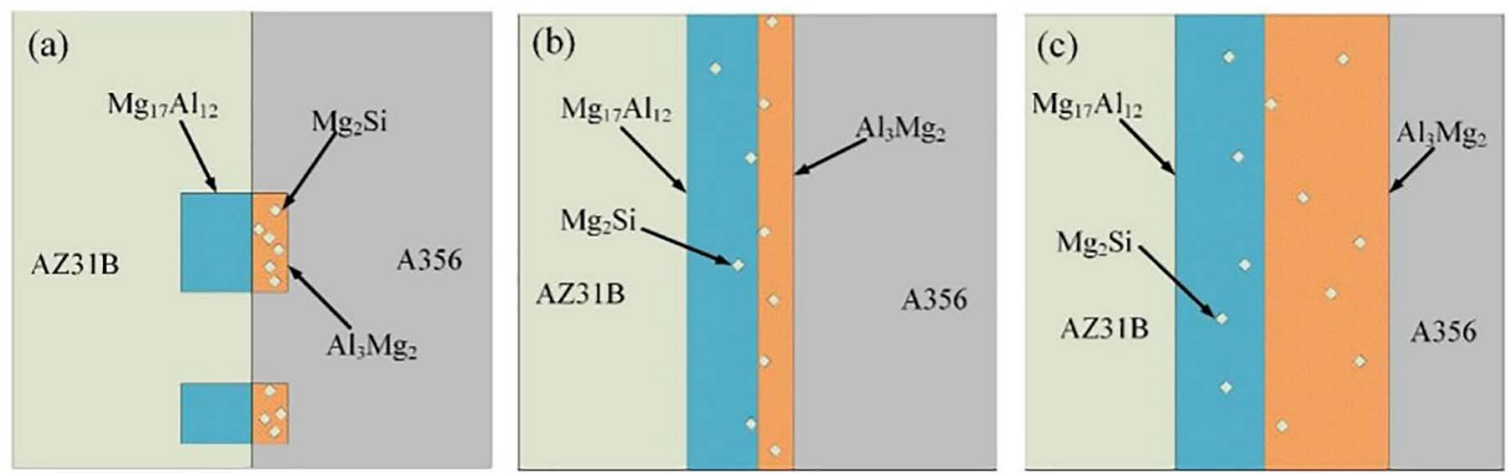

Figure 9. Schematic diagrams of diffusion process: (a) annealing temperature $<250{ }^{\circ} \mathrm{C}$, (b) annealing temperature $=250{ }^{\circ} \mathrm{C}$, (c) annealing temperature $>250{ }^{\circ} \mathrm{C}$.

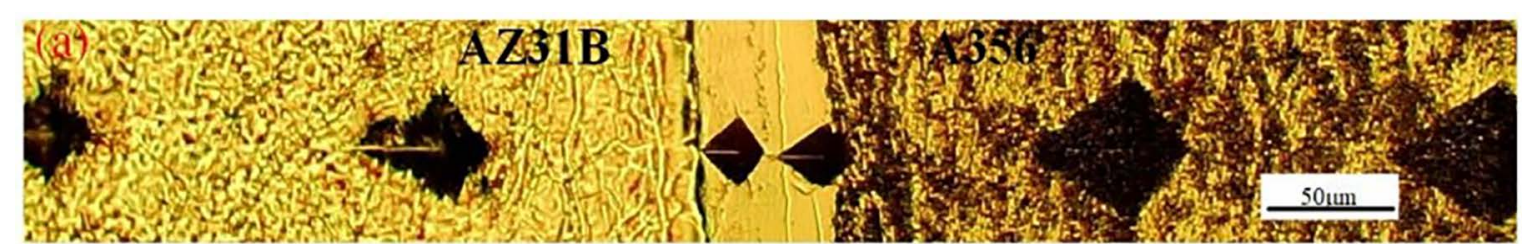

(b)
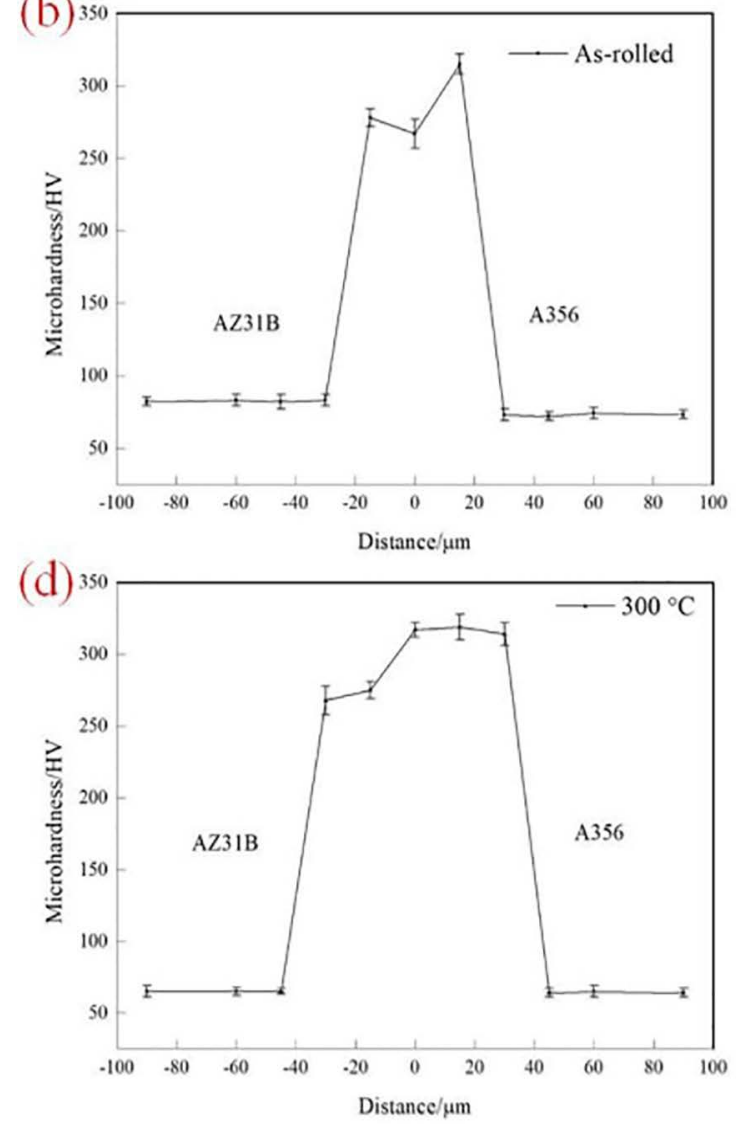

(c)
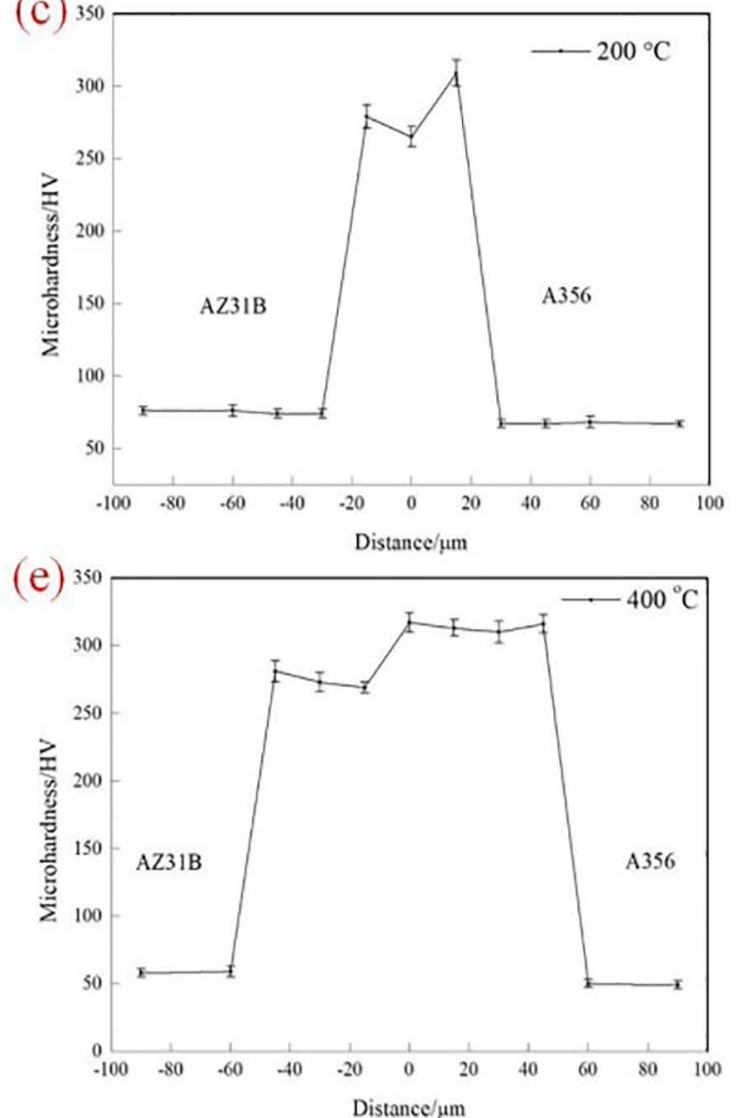

Figure 10. Vickers microhardness test results across the interfacial transition zone under different conditions (annealed for $180 \mathrm{~min}$ ): (a) indentations of $400{ }^{\circ} \mathrm{C}$; microhardness distribution: (b) as-rolled, (c) $200{ }^{\circ} \mathrm{C}$, (d) $300{ }^{\circ} \mathrm{C}$, (e) $400{ }^{\circ} \mathrm{C}$. 
By observing the changes in surface microhardness of the samples, it is found that the microhardness of the interfacial transition zone underwent a rapid increase compared with that of the bilateral alloys, which is due to the presence of intermetallic compounds $\mathrm{Al}_{3} \mathrm{Mg}_{2}(315 \mathrm{HV})$ and $\mathrm{Mg}_{17} \mathrm{Al}_{12}(275 \mathrm{HV})$ in the interfacial transition zone ${ }^{5}$. It can also be observed that the average microhardness of the bilateral alloys after annealing were lower than those of the as-rolled specimens (83 HV for the AZ31B magnesium alloy and $74 \mathrm{HV}$ for the A356 aluminium alloy) and decrease gradually with increased annealing temperature. The explanation for this phenomenon is the annealing process caused dislocation slip in the grain which was mutually annihilated after encounters between unlike dislocations ${ }^{26}$. Simultaneously, the dislocation density in the new equiaxial crystal nuclei formed by recrystallization is less than that in other grains. As a result, the density of dislocations decreases, the work hardening caused by the rolling process is eliminated, and the effect of dislocation strengthening is reduced. Therefore, all average microhardness values of these bilateral alloys decreased after annealing.

\subsection{Shear Strength}

The interface joint of the $\mathrm{Mg} / \mathrm{Al}$ composite plate is the weakest part of the system. Therefore, tests measuring the interface bond strength of composite plates can help our understanding of the mechanical properties of such materials. The photograph and dimensions of such shear samples which based on the GB/T 228.1-2010 are presented in Figures 11a and b, respectively. Figure 12 shows the shear strength test data from samples loaded under different conditions, all shear strength values are expressed as the average values obtained from at least five different samples. As can be seen from Figure 12, the shear strength first increases and then decreases. The reasons for this are presumed to be related to the fact that, when the annealing temperature was $150^{\circ} \mathrm{C}$ or $200^{\circ} \mathrm{C}$, a small number of intermetallic compounds reach sufficient energy for diffusion activation and migration so start to diffuse from the interface transition zone to the bilateral alloys. Simultaneously, the atoms on both sides of the alloys also diffuse to the interfacial transition zone. The mode of interface bonding changes from single mechanical bonding to both mechanical bonding and metallurgical bonding.
So the shear strength of the $\mathrm{Mg} / \mathrm{Al}$ composite plates undergoes a modest increase compared with the as-rolled specimens: the shear strength of these composite plates reaches a maximum of $116 \mathrm{MPa}$ when the annealing temperature was $200^{\circ} \mathrm{C}$. As the annealing temperature reaches $250{ }^{\circ} \mathrm{C}$, recrystallization proceeds on the magnesium side of the composite plates whose areas suffering distortion generate new crystal nuclei. Since the recrystallization volume fraction on the magnesium side has reached $96 \%$ at the same time, the density of dislocations formed during deformation is reduced, and most of the strain energy inside the grains is fully released, yet the thermodynamic and kinetic conditions required for the formation of intermetallic compounds have been met, so new intermetallic compounds begin to form, and the intermetallic compounds are continuously distributed in the interfacial transition zone. At this point, the continuous hard and brittle phases play a role in internal cleavage, and the adverse effects thereof far exceed than strengthening effects of grain size reduction, so the interface bonding strength starts to decrease. When the annealing temperature exceeds $250^{\circ} \mathrm{C}$, on the one hand, the grains continue to grow after complete recrystallization, and such grain coarsening has negative effects on interface bonding strength. On the other hand, the width of the interfacial transition zone increases exponentially with the increase of annealing temperature, and the volume fraction of the hard and brittle phases in the interfacial transition zone increases significantly. Therefore, the shear strength of $\mathrm{Mg} / \mathrm{Al}$ composite plates decreases.

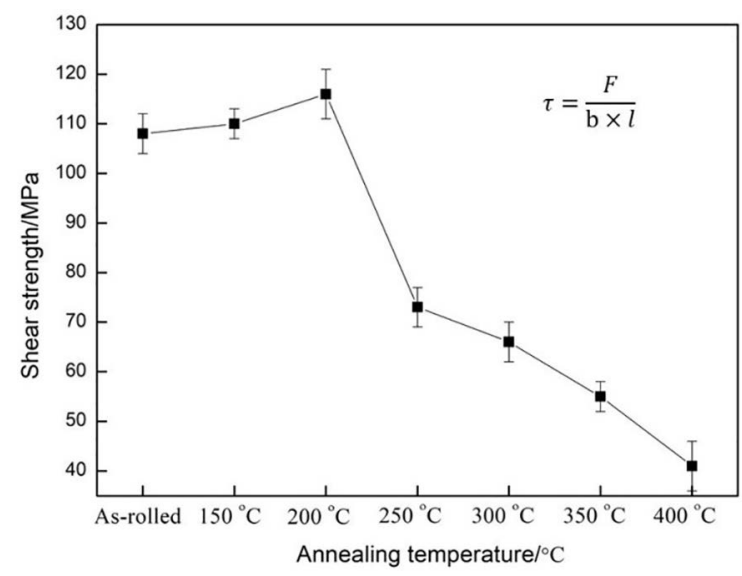

Figure 12. Shear strength under different conditions (annealed for $180 \mathrm{~min}$ ).
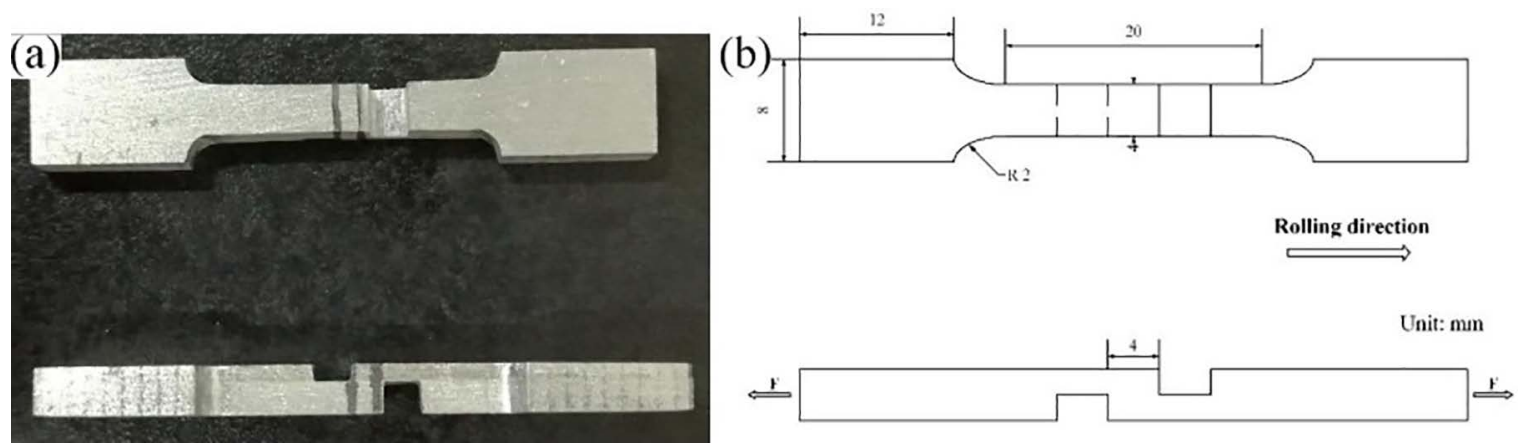

Figure 11. The photograph and dimensions of shear samples. 

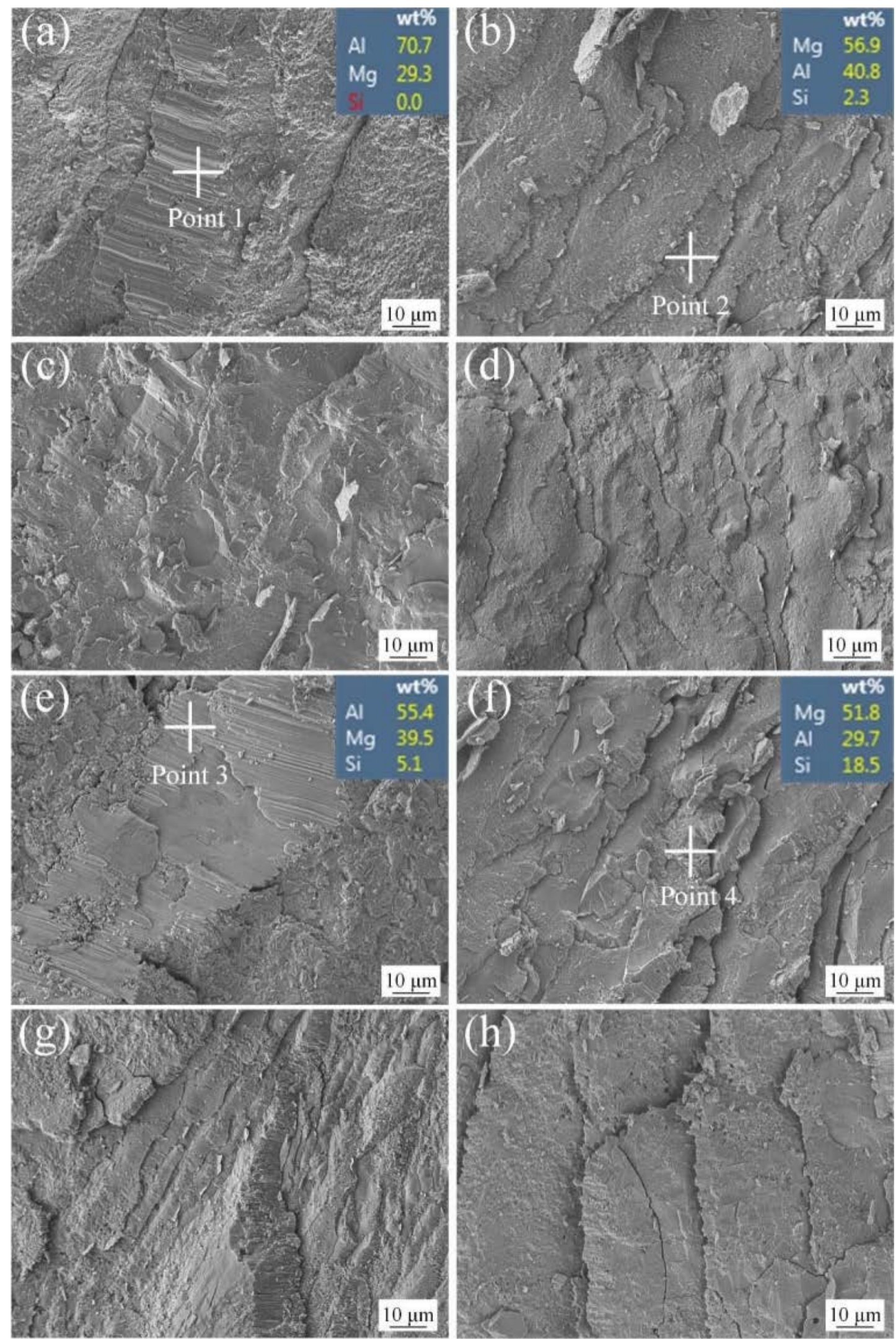

Figure 13. The SEM fractographs of the shear samples under various conditions: as-rolled (a) and (b), annealed for 180 min at $200{ }^{\circ} \mathrm{C} \mathrm{(c)} \mathrm{and} \mathrm{(d),} 300{ }^{\circ} \mathrm{C}$ (e) and (f), $400{ }^{\circ} \mathrm{C}(\mathrm{g})$ and (h), where (a), (c), (e) and (g) show the A356 side while (b), (d), (f) and (h) show the AZ31B side. 


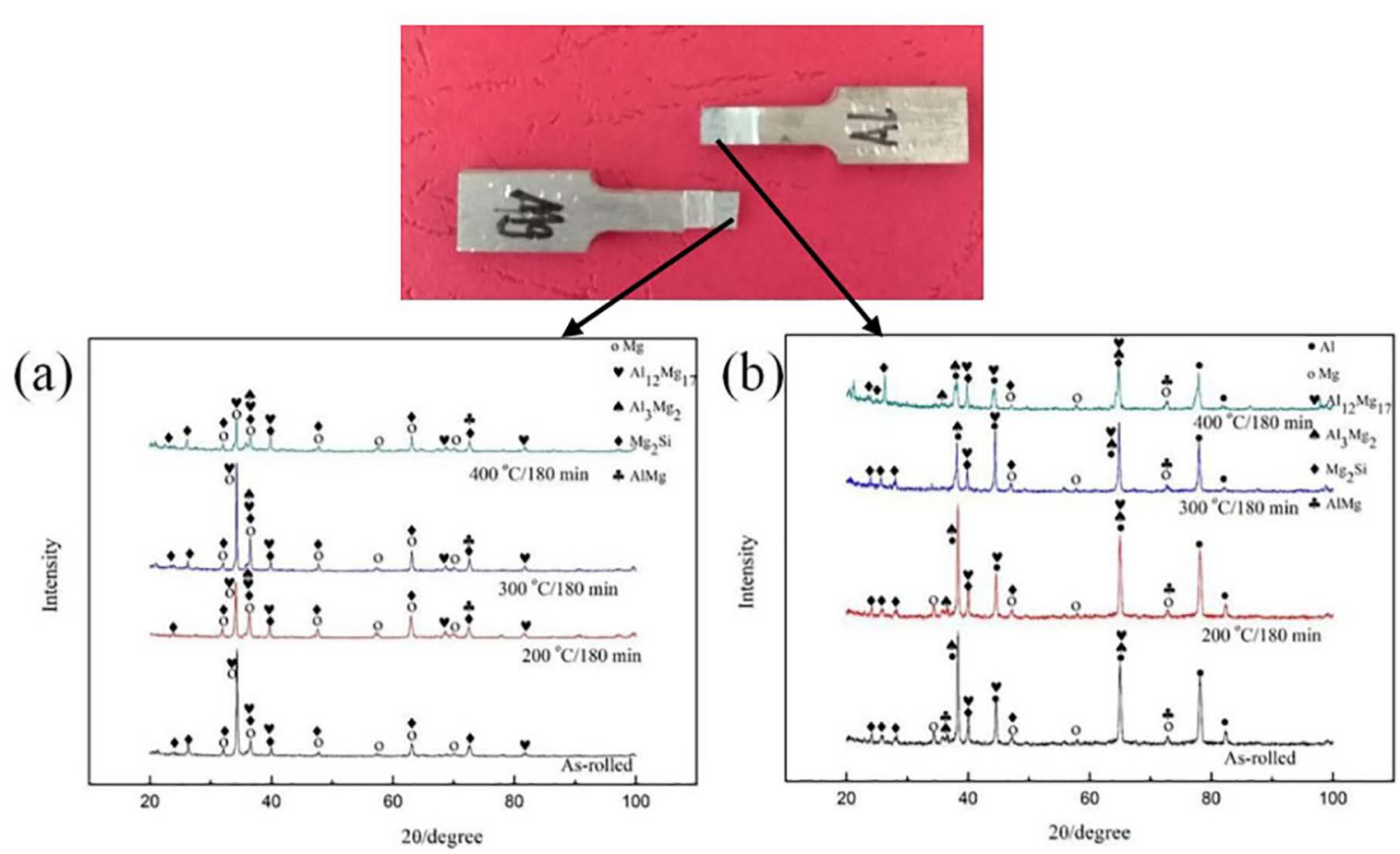

Figure 14. XRD patterns of the shear fractures on (a) the side-nearest the AZ31B and (b) the side nearest the A356.

\subsection{Shear Fractograph Analysis}

Figure 13 shows the SEM fractographs of the shear samples under various conditions. It can be seen that there had been no macroscopic plastic deformation on the fracture surface, and the fractures appeared to be relatively flat. There are several parallel and continuous cracks which are characterized by river pattern around the fractures near the AZ31B, where there are also numerous small facets. At the same time, several parallel but discontinuous tearing edges occupy the majority of fractures near A356. In combination with the crystal lattice type of the two alloys, it is showed that the cleavage fracture occurs on theAZ31B side with quasi-cleavage fracture on the A356 side, both of which are brittle fractures ${ }^{33}$.The location of the hard and brittle phases can be sought along the branch of the crack towards the trunk ${ }^{34}$.Local point scanning was performed using SEM-EDS and the compositions of each point are shown in Figure 13. Due to the hard and brittle phases present in the interfacial transition zone of $\mathrm{Mg} /$ Al composite plates, when a shear stress is applied to the interface thereof, stress concentrations are generated in the hard and brittle phases, resulting in the initiation of cracks, which rapidly expand until interface separation occurs. When the composite plate cracks, some hard and brittle phases spall from the interface simultaneously. As shown in Figure 13, there are a few small pits on the surface of the fracture. Therefore, the hard and brittle phases are the causes of fracture of $\mathrm{Mg} / \mathrm{Al}$ composite plates.
Comparing Figures $13 \mathrm{~b}$ and $\mathrm{d}$, it is found that the depth of fracture layers is similar. It can be observed that the depth of both the $\mathrm{Al}$ and $\mathrm{Mg}$ fracture layers when the annealing temperature was at, or above, $300^{\circ} \mathrm{C}$ are greatly increased. It also indirectly proves that the volume fraction of hard and brittle phases which occupy the interfacial transition zone has greatly improved than previous conditions when the annealing temperature at, or above, $300^{\circ} \mathrm{C}$. The number of cracks, and the depth of the fracture layers, both increased meanwhile.

\subsection{XRD Analysis}

The XRD patterns of the shear fractures at the side near AZ31B and the side near A356 are shown in Figures 14a and $b$, respectively ${ }^{34}$. The scanning range and speed are set to $20^{\circ}$ to $100^{\circ}$ and $10^{\circ} / \mathrm{min}$, respectively. The results indicate that intermetallic compounds are found in both shear fractures of the as-rolled and the as-annealed specimens, and the types of intermetallic compounds are identical to those on the shear fracture of the alloy at same side. At the same time, there are no $\mathrm{Al}$ elements on the fracture of AZ31B side. On the one hand, these phenomena prove that the interdiffusion ability of $\mathrm{Mg}$ atoms is stronger than that of $\mathrm{Al}$ atoms ${ }^{12}$; on the other hand, these also indicate that the site of shear fracture is located in the intermediate region, so the hard and brittle phases directly lead to shear fracture. The $\mathrm{Al}_{12} \mathrm{Mg}_{17}$ content on the side near the AZ31B is markedly higher than that of $\mathrm{Al}_{3} \mathrm{Mg}_{2}$, and that of $\mathrm{Al}_{3} \mathrm{Mg}_{2}$ on the side near the $\mathrm{A} 356$ is higher than that of $\mathrm{Al}_{12} \mathrm{Mg}_{17}$. 
Moreover, a small amount of AlMg phases are found in the fracture on both sides. From the perspective of thermodynamics and kinetics, compared with $\mathrm{Al}_{12} \mathrm{Mg}_{17}$ and $\mathrm{Al}_{3} \mathrm{Mg}_{2}$, the $\mathrm{AlMg}$ phase has a narrower solubility range and a smaller diffusion coefficient, which does not contribute to the formation and growth of the AlMg phase ${ }^{32}$. Therefore, the influence of $\mathrm{AlMg}$ on the interface can be neglected. Based on the data shown in Figures 13 and 14, it can be speculated that the shear fracture of composite plates are caused by the presence of three hard and brittle phases, $\mathrm{Al}_{12} \mathrm{Mg}_{17}, \mathrm{Al}_{3} \mathrm{Mg}_{2}$, and $\mathrm{Mg}_{2} \mathrm{Si}$ in the intermediate region.

\section{Conclusions}

In this study, solid-liquid cast-rolling is a simple and valid method with which to fabricate AZ31B/A356 composite plates of sound appearance and good bonding. To eliminate the work hardening of the rolled $\mathrm{Mg} / \mathrm{Al}$ composite plates, a subsequent annealing process was used and the effects thereof on the relationship between microstructure evolution and mechanical properties of composite plates were investigated. The following conclusions were obtained:

1. The interfacial transition zone of the $\mathrm{Mg} / \mathrm{Al}$ composite plate can be divided into three regions: a $\mathrm{Mg}$ transition region (region I) consisting of $\delta-\mathrm{Mg}, \mathrm{Mg}_{17} \mathrm{Al}_{12}$ and $\mathrm{Mg}_{2} \mathrm{Si}$ formed near the AZ31B side, and $\mathrm{Al}$ transition region (region II) consisting of $\alpha-\mathrm{Al}_{1} \mathrm{Al}_{3} \mathrm{Mg}_{2}$ and $\mathrm{Mg}_{2} \mathrm{Si}$ formed near the $\mathrm{A} 356$ side, and an intermediate region (region III) composed of $\mathrm{Mg}_{17} \mathrm{Al}_{12}, \mathrm{Mg}_{2} \mathrm{Si}$, and $\mathrm{Al}_{3} \mathrm{Mg}_{2}$, respectively. Only when the annealing temperature reaches, or exceeds, $300^{\circ} \mathrm{C}$, was the width of region II significantly greater than that of region I.

2. The microhardness of the interfacial transition zone was higher than that of bilateral alloys, and the microhardness of the bilateral alloys gradually decreased with the increase of annealing temperature.

3. When annealing temperature did not exceed 200 ${ }^{\circ} \mathrm{C}$, the bonding strength of the composite plates increased, and the shear strength of the composite plates reached its maximum value of $116 \mathrm{MPa}$ when the annealing temperature reached $200{ }^{\circ} \mathrm{C}$. When the annealing temperature was $250^{\circ} \mathrm{C}$, the volume fraction of grain recrystallization on the side with the magnesium alloy reached $96 \%$ and new intermetallic compounds began to be generated. These intermetallic compounds were distributed continuously within the interfacial transition zone, and the shear strength thereof began to decrease. When the annealing temperature exceeded $250{ }^{\circ} \mathrm{C}$, the relationship linking the width of the interfacial transition zone, the annealing temperature, and time could be described by the following kinetic model: $(\Delta X)^{2}=2.07 \times 10^{4} \exp \left(-\frac{60407}{R T}\right)\left(t-11.54 \exp \frac{21211}{R T}\right)$.
4. The hard and brittle phases caused fracture of the $\mathrm{Mg} / \mathrm{Al}$ composite plates, where cleavage fracture and quasi-cleavage fracture occurred at the side containing AZ31B and that containing A356, respectively (both of these were brittle fractures).

\section{Acknowledgements}

The study was supported by the National Natural Science Foundation of China (Grant no. 51464031) and the Key Research and Development Programme of Gansu Province (Grant no. 17YF1GA021).

\section{References}

1. Zhu SQ, Ringer SP. On the role of twinning and stacking faults on the crystal plasticity and grain refinement in magnesium alloys. Acta Materialia. 2018;144:365-375.

2. Alaneme KK, Okotete EA. Enhancing plastic deformability of $\mathrm{Mg}$ and its alloys-A review of traditional and nascent developments. Journal of Magnesium and Alloys. 2017;5(4):460-475.

3. Xu W, Birbilis N, Sha G, Wang Y, Daniels JE, Xiao Y, et al. A high-specific-strength and corrosion-resistant magnesium alloy. Nature Materials. 2015;14:1229-1235.

4. Naik BS, Cao X, Wanjara P, Friedman J, Chen D. Residual Stresses and Tensile Properties of Friction Stir Welded AZ31B-H24 Magnesium Alloy in Lap Configuration. Metallurgical and Materials Transactions B. 2015;46(4):1626-1637.

5. Macwan A, Jiang XQ, Li C, Chen DL. Effect of annealing on interface microstructures and tensile properties of rolled $\mathrm{Al} / \mathrm{Mg} /$ Al tri-layer clad sheets. Materials Science and Engineering: A. 2013;587:344-351.

6. Chen Z, Wang D, Cao X, Yang W, Wang W. Influence of multi-pass rolling and subsequent annealing on the interface microstructure and mechanical properties of the explosive welding $\mathrm{Mg} / \mathrm{Al}$ composite plates. Materials Science and Engineering: A. 2018;723:97-108.

7. Zhao Z, Gao Q, Hou J, Sun Z, Chen F. Determining the microstructure and properties of magnesium aluminum composite panels by hot rolling and annealing. Journal of Magnesium and Alloys. 2016;4(3):242-248.

8. Jafarian M, Khodabandeh A, Manafi S. Evaluation of diffusion welding of 6061 aluminum and AZ31 magnesium alloys without using an interlayer. Materials \& Design (1980-2015). 2015;65:160-164.

9. Kim EY, Cho JH, Kim HW, Choi SH. Evolution of deformation texture in $\mathrm{Al} / \mathrm{Al}-\mathrm{Mg} / \mathrm{Al}$ composite sheets during cold-roll cladding. Materials Science \& Engineering: A. 2011;530:244-252.

10. Tayal RK, Kumar S, Singh V, Gupta A, Ujjawal D. Experimental Investigation and Evaluation of Joint Strength of A356/Mg Bimetallic Fabricated Using Compound Casting Process. International Journal of Metalcasting. 2018. DOI: https://doi. org/10.1007/s40962-018-0288-2 
11. Yang W, Cao X, Wang L, Chen Z, Wang W, Wang D. Microstructure and Mechanical Properties of AA6061/AZ31B/AA6061 Composite Plates Fabricated by Vertical Explosive Welding and Subsequent Hot Rolling. Materials Research. 2018;21(6):e20180350.

12. Wang J, Li Y, Huang W. Interface microstructure and diffusion kinetics in diffusion bonded $\mathrm{Mg} / \mathrm{Al}$ joint. Reaction Kinetics and Catalysis Letters. 2008;95(1):71-79.

13. Xu G, Chen Y, Luo A, Sachdev AK. Effect of aluminum surface treatment on structures and properties of liquid-solid diffusion bonding interface of AM60/A390. Chinese Journal of Nonferrous Metals. 2014;24(4):855-862.

14. Yan YB, Zhang ZW, Shen W, Wang JH, Zhang LK, Chin BA. Microstructure and properties of magnesium AZ31B-aluminum 7075 explosively welded composite plate. Materials Science and Engineering: A. 2010;527(9):2241-2245.

15. Jia RL, Duan HP, Guo F, Zhai XW, Liang YH. Study on the Corrosion Resistance and Wear Resistance of Micro-Arc Oxidation Coatings on the Clad Plate of Aluminum and Magnesium Alloy. Advanced Materials Research. 2011;189-193:1248-1252.

16. Wang D, Cao X, Wang L, Cao M, Wang W. Influence of hot rolling on the interface microstructure and mechanical properties of explosive welded $\mathrm{Mg} / \mathrm{Al}$ composite plates. Journal of Materials Research. 2017;32(4):863-873.

17. Liu JC, Hu J, Nie XY, Li HX, Du Q, Zhuang JS, et al. The interface bonding mechanism and related mechanical properties of $\mathrm{Mg} / \mathrm{Al}$ compound materials fabricated by insert molding. Materials Science and Engineering: A. 2015;635:70-76.

18. Zhang H, Chen Y, Luo AA. Improved Interfacial Bonding in Magnesium/Aluminum Overcasting Systems by Aluminum Surface Treatments. Metallurgical and Materials Transactions B. 2014;45(6):2495-2503.

19. Xu G, Luo AA, Chen Y, Sachdev AK. Interfacial phenomena in magnesium/aluminum bi-metallic castings. Materials Science and Engineering: A. 2014;595:154-158.

20. Lee KS, Lee YS, Kwon YN. Influence of secondary warm rolling on the interface microstructure and mechanical properties of a roll-bonded three-ply $\mathrm{Al} / \mathrm{Mg} / \mathrm{Al}$ sheet. Materials Science and Engineering: A. 2014;606:205-213.

21. Zhang XP, Yang TH, Castagne S, Wang J. Microstructure; bonding strength and thickness ratio of $\mathrm{Al} / \mathrm{Mg} / \mathrm{Al}$ alloy laminated composites prepared by hot rolling. Materials Science and Engineering: A. 2011;528(4-5):1954-1960.

22. Luo C, Liang W, Chen Z, Zhang J, Chi C, Yang F. Effect of high temperature annealing and subsequent hot rolling on microstructural evolution at the bond-interface of $\mathrm{Al} / \mathrm{Mg} / \mathrm{Al}$ alloy laminated composites. Materials Characterization. 2013;84:34-40.
23. Nie H, Liang W, Chen H, Zheng L, Chi C, Li X. Effect of annealing on the microstructures and mechanical properties of $\mathrm{Al} / \mathrm{Mg} / \mathrm{Al}$ laminates. Materials Science and Engineering. A. 2018;732:6-13.

24. Fronczek DM, Chulist R, Litynska-Dobrzynska L, Kac S, Schell N, Kania Z, et al. Microstructure and kinetics of intermetallic phase growth of three-layered A1050/AZ31/A1050 clads prepared by explosive welding combined with subsequent annealing. Materials \& Design. 2017;130:120-130.

25. Kim JS, Lee KS, Kwon YN, Lee BJ, Chang YW, Lee S. Improvement of interfacial bonding strength in roll-bonded $\mathrm{Mg} / \mathrm{Al}$ clad sheets through annealing and secondary rolling process. Materials Science and Engineering: A. 2015;628:1-10.

26. Mittemeijer EJ. Recovery, Recrystallization and Grain Growth. In: Mittemeijer EJ. Fundamentals of Materials Science. Berlin Heidelberg: Springer; 2011. p. 463-496.

27. Zhang N, Wang W, Cao X, Wu J. The effect of annealing on the interface microstructure and mechanical characteristics of AZ31B/AA6061 composite plates fabricated by explosive welding. Materials \& Design (1980-2015). 2015;65:1100-1109.

28. Zhou Y, Zhu Y, Zhu Y, Li L. Phase transformation, kinetics and thermodynamics during the combustion synthesis of $\mathrm{Mg}_{2} \mathrm{Al}_{3}$ alloy. Journal of Alloys and Compounds. 2015;628:257-262.

29. Yan XY, Chang YA, Zhang F. A Thermodynamic Analysis of the Mg-Si System. Journal of Phase Equilibria. 2000;21(4):379-384.

30. Li Y, Liu P, Wang J, Ma H. XRD and SEM analysis near the diffusion bonding interface of $\mathrm{Mg} / \mathrm{Al}$ dissimilar materials. Vacuum. 2007;82(1):15-19.

31. Sun B, Li S, Imai H, Umeda J, Kondoh K. Synthesis kinetics of $\mathrm{Mg}_{2} \mathrm{Si}$ and solid-state formation of $\mathrm{Mg}-\mathrm{Mg}_{2} \mathrm{Si}$ composite. Powder Technology. 2012;217:157-162.

32. Brennan S, Bermudez K, Kulkarni NS, Sohn Y. Interdiffusion in the Mg-Al System and Intrinsic Diffusion in $\beta-\mathrm{Mg}_{2} \mathrm{Al}_{3}$. Metallurgical \& Materials Transactions A. 2012;43(11):40434052.

33. Ma L, Qiao P, Long W, He D, Li X. Interface characteristics and mechanical properties of the induction brazed joint of magnesium alloy AZ31B with an Al-based filler metal. Materials \& Design. 2012;37:465-469.

34. Zhu B, Liang W, Li X. Interfacial microstructure, bonding strength and fracture of magnesium-aluminum laminated composite plates fabricated by direct hot pressing. Materials Science and Engineering: A. 2011;528(21):6584-6588. 